\title{
Transcriptional network in ovarian cancer cell line SKOV3 treated with Pinellia pedatisecta Schott extract
}

\author{
LI ZHOU $^{1,2^{*}}$, TENG XU $^{3 *}$, YING ZHANG ${ }^{3}$, MEI ZHU $^{3}$, WEN ZHU $^{3}$, ZIQIANG WANG $^{3}$, \\ HANGZHI GU ${ }^{3}$, HANCHU WANG ${ }^{3}$, PEIZHEN LI ${ }^{3}$, JUN YING ${ }^{3}$, LEI YANG ${ }^{3}$, PING REN ${ }^{3}$, \\ JINSONG $\mathrm{LI}^{3}$, ZUYUAN XU ${ }^{3}$, LIYAN NI ${ }^{4}$, QIYU BAO ${ }^{1,3}$ and JINDONG CHEN ${ }^{5}$ \\ ${ }^{1}$ The First Affiliated Hospital, Wenzhou Medical University; ${ }^{2}$ Wenzhou Traditional Chinese Medical Hospital, Wenzhou, \\ Zhejiang 325000; ${ }^{3}$ Institute of Biomedical Informatics/Zhejiang Provincial Key Laboratory of Medical Genetics, \\ Wenzhou Medical University, Wenzhou, Zhejiang 325035; ${ }^{4}$ The Second Affiliated Hospital, Wenzhou Medical University, \\ Wenzhou, Zhejiang 325000, P.R. China; ${ }^{5}$ University of Rochester Medical Center, Rochester, NY 14642, USA
}

Received January 11, 2016; Accepted February 18, 2016

DOI: $10.3892 /$ or.2016.4779

\begin{abstract}
Ovarian cancer is the most lethal disease among the malignant tumors of female reproductive organs. Few successful therapeutic options exist for patients with ovarian cancer. The common therapeutic methods are surgical operation, chemotherapy, radiotherapy, and combination of these treatments. In recent years, studies have indicated that Pinellia pedatisecta Schott (PPS), a traditional Chinese medicine, could inhibit tumor growth. In this study, we demonstrated that PPS extract could induce apoptosis in SKOV3 cells in a dose- and time-dependent manner. We further conducted transcriptome sequencing on PPS extract-treated SKOV3 cells along with controls, and identified 1,754 transcripts whose expression differs at least 3-fold over the controls. These differentially expressed transcripts include the apoptosis-related genes such as the caspase family members, and were significantly enriched in steroid biosynthesis in the KEGG pathway database compared with the transcriptome background. Most of the differentially expressed transcripts from this pathway were upregulated in PPS extract-treated cell line, indicating that PPS extract-induced apoptosis was accompanied by increased steroid biosynthesis (e.g. zymosterol). These results suggest that PPS extract could be a new cytostatic therapeutic agent for ovarian cancer.
\end{abstract}

Correspondence to: Dr Li Zhou, The First Affiliated Hospital, Wenzhou Medical University, Wenzhou, Zhejiang 325000, P.R. China E-mail: 1yly20030831@163.com

Dr Qiyu Bao, Institute of Biomedical Informatics/Zhejiang Provincial Key Laboratory of Medical Genetics, Wenzhou Medical University, Wenzhou, Zhejiang 325035, P.R. China

E-mail: baoqy@genomics.org.cn

${ }^{*}$ Contributed equally

Key words: ovarian cancer, SKOV3, Pinellia pedatisecta Schott, apoptosis, transcriptome sequencing, differential gene expression

\section{Introduction}

Epithelial ovarian cancer (EOC), the most common ovarian malignancy, continues to be the leading cause of death among gynecological malignancies (1). The poor survival from EOC is due to the high percentage of patients diagnosed at an advanced stage and a lack of effective treatment (2). Currently the standard treatment protocol used in the initial management of advanced-stage ovarian cancer is primary cytoreductive surgery, followed by platinum/taxane combination chemotherapy. Approximately $70 \%$ of patients will have a complete clinical response to this initial therapy, indicated by an absence of clinically detectable residual disease based on clinical exam, radiologic imaging, or measurement of serum tumor marker CA125 (3). Unfortunately, the majority of these patients will eventually develop recurrence or persistent platinum-resistant disease (4). Therefore, more effective treatments for advanced ovarian cancer are urgently required (5).

Pinellia pedatisecta Schott (PPS), a traditional Chinese medicine (TCM), has been used, based on many TCM books, to treat several disorders. In the 1970s, Pedate Pinellia Rhizome was used in the Obstetrics and Gynecology Hospital of Fudan University to treat 247 cervical cancer patients with a total effective rate of $81.5 \%$. Following, Li et al found that a novel lipid-soluble extract (PE) from PPS can induce apoptosis in human cervical cancer cells with few side effects on normal cells, suggesting that PPS extract could be used as a potential drug for cervical cancer treatment (6). In addition, Sun et al found that total PPS extract can inhibit mouse sarcoma-180 growth in vivo by direct intraperitoneal injection (7). However, the pharmacological mechanism of this action has not been established.

In this study, we first examined whether the PPS extract component could induce apoptosis and exert proliferation inhibition on ovarian cancer cell line SKOV3. To determine how PPS extract affects apoptosis and tumor inhibition, we performed high throughput mRNA sequencing and bioinformatics analysis to determine transcriptome difference between PPS-treated SKOV3 cells and controls. 


\section{Materials and methods}

Cell line. The ovarian cancer cell line SKOV3 was purchased from Shanghai Institutes for Biological Sciences and maintained as recommended by the supplier (American Type Culture Collection, Rockville, MD, USA). Cells were cultured in RPMI-1640 supplemented with $10 \%$ fetal bovine serum (FBS), $1 \%$ sodium pyruvate, and $1 \%$ nonessential amino acids. All tissue culture reagents were obtained from Sigma-Aldrich (St. Louis, MO, USA).

Preparation of total extract from PPS. Fresh PPS was collected from Xuchang, Henan Province, China. It was washed and peeled, and ground to generate a homogenate with normal saline. The homogenate was centrifuged at $3000 \mathrm{rpm}$ and $4^{\circ} \mathrm{C}$ for $20 \mathrm{~min}$ and the supernatant was retrieved. Crude extract of PPS was obtained by two times gradient sedimentation with acetone $(\mathrm{V} / \mathrm{V})$. The sediments was dissolved into $0.9 \% \mathrm{NaCl}$ $(\mathrm{m} / \mathrm{m})$ and followed by dialysis in distilled water at $4^{\circ} \mathrm{C}$ for $48 \mathrm{~h}$. After high-speed centrifugation, the supernatant was extracted as the final total extract. Extract protein concentrations were measured by bicinchoninic acid (BCA) method. Detection of phosphorus, saccharide and lipid protein in the total extract was measured by ammonium molybdate spectrophotometry, Molisch's test and Sudan black B staining method, respectively.

Cytotoxicity assay. SKOV3 cells at logarithmic growth phase were seeded at 5000 cells per well in 96-well culture plates and cultured for $24 \mathrm{~h}$. The PPS extract protein at increasing concentrations $(0.8,4,20,100,200,300,400 \mu \mathrm{g} / \mathrm{ml})$ was added to the wells. After $72 \mathrm{~h}, \mathrm{CCK}-8(10 \% \mathrm{~V} / \mathrm{V})$ was added to the culture and incubated for $1 \mathrm{~h}$. With $630 \mathrm{~nm}$ wavelength as the reference, the absorption values at $450 \mathrm{~nm}$ were collected for analysis in an automatic ELISA detection instrument. Medium alone was used as the blank control. Cells without drug treatment or with cisplatin (DDP) treatment were used as negative or positive controls, respectively. All the experiments were replicated six times.

Flow cytometry analysis. SKOV3 cells in logarithmic growth phase were seeded in 6-well plates at approximately $8 \times 10^{4}$ cells per well and cultured for $24 \mathrm{~h}$. Increasing concentrations of the protein extract of PPS $(0,20,50,100,200,400 \mu \mathrm{g} / \mathrm{ml})$ were added to the wells and cells were cultured for an additional $72 \mathrm{~h}$ at $37^{\circ} \mathrm{C}$. The cells were trypsinized, washed twice with ice-cold PBS extract, adjusted to $1 \times 10^{6}$ cells $/ \mathrm{ml}$ and fixed with $70 \%$ ethanol. Then, $100 \mu \mathrm{l}$ cell suspension aliquot was taken to each labeled tube, followed by adding $10 \mu \mathrm{l}$ Annexin V-FITC

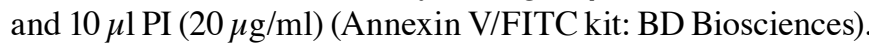
After 20 min incubation in darkness at room temperature, $400 \mu \mathrm{l}$ PBS binding buffer was then added and cell apoptosis was detected immediately by flow cytometry (BD Biosciences Clontech, San Jose, CA, USA) (within 30 min after adding PBS binding buffer). Samples in triplicates were examined. SKOV3 cells without treatment were used as the reference. Data analysis was conducted using the Cell Quest software.

Transcriptome sequencing. SKOV3 cells and those treated with $200 \mu \mathrm{g} / \mathrm{ml}$ PPS extract for $72 \mathrm{~h}$ were subjected to mRNASeq library construction and transcriptome sequencing.
Approximately $10^{8}$ cells from each group were collected after PBS washes. Oligo(dT) beads were used to capture poly(A) mRNA after total RNA was extracted. Each poly(A)-enriched RNA sample was chemically fragmented into small pieces using divalent cations at $94^{\circ} \mathrm{C}$ for $5 \mathrm{~min}$. The fragmented RNA was reverse-transcribed into cDNA using random hexamer primers containing a tagging sequence at the 3 ' end and a SuperScript III Double-Stranded cDNA synthesis kit according to the manufacturer's protocol (Invitrogen, Carlsbad, CA, USA). The double-stranded cDNA was subjected to end-repair and further $3^{\prime}$ terminal tagging by the addition of 5' DNA adaptors and T4 DNA ligase with overnight incubation at $16^{\circ} \mathrm{C}$ for $16 \mathrm{~h}$. The targeted di-tagged cDNA was purified by polyacrylamide gel electrophoresis and gel excision $(200 \pm 25 \mathrm{bp})$. The clean di-tagged cDNA was enriched by 18 PCR cycles with primer pairs annealed to the tagging sequences of the di-tagged cDNA. Library purification by PAGE removed any residual nucleotides, PCR primers and small amplicons. Two paired-end libraries were sequenced using the HiSeq2000 platform (Illumina). The initial short reads from this study are being submitted to the NCBI sequence read archive database and the accessions will be released soon.

Bioinformatics analysis. The raw Illumina/Solexa reads of SKOV3 cells and PPS extract-treated cells were subjected to adapter trimming and low quality filtering using the Trimmomatic program (8). The high quality clean reads were aligned to the human genome using TopHat (9). Human genome (hg19) sequence and gene annotation were obtained from the UCSC Genome Browser (http://genome.ucsc.edu/). Cuffdiff was used to perform differential gene expression profiling with default parameters $(10,11)$. The significantly differentially expressed transcripts (DETs) between SKOV3 and PPS extract-treated cell line were selected using the following criteria: i) if the FPKM value for a certain transcript in both samples was $>1$, the difference between them should be at least 3 -fold. ii) If the FPKM value for a certain transcript in one sample was $<1$, the FPKM value for this gene in the paired sample should be $>3$. Mapping transcripts to the KEGG pathway were conducted using the BLASTX and followed by custom scripts (12). KEGG pathway enrichment analysis of the DETs compared with transcriptome background (Cuffdiff detected transcript status as 'OK') was performed by hypergenometric distribution testing using the Phyper function of the $\mathrm{R}$ software package (http://www.r-project.org/). Bonferroni correction was used to adjust $\mathrm{P}$-value for each pathway.

Quantitative real-time PCR validation of $m R N A-S e q$ data. The mRNAs which have been used to perform mRNA-Seq experiments from two cell lines were used for qPCR validation. Total RNA from each sample was treated with DNase I before reverse transcription by SuperScript III double-stranded cDNA synthesis kit. Ten intron-spanning target gene primers and two endogenous control (18s rRNA and GAPDH) primers were designed using Primer 5.0 for qPCR experiment. SYBR Green I based qPCR was performed according to the routine protocols (13) on a 7500 Real-time PCR System (Applied Biosystems, Foster City, CA, USA) and three technical replicates were performed for all the genes in each sample. Gene 

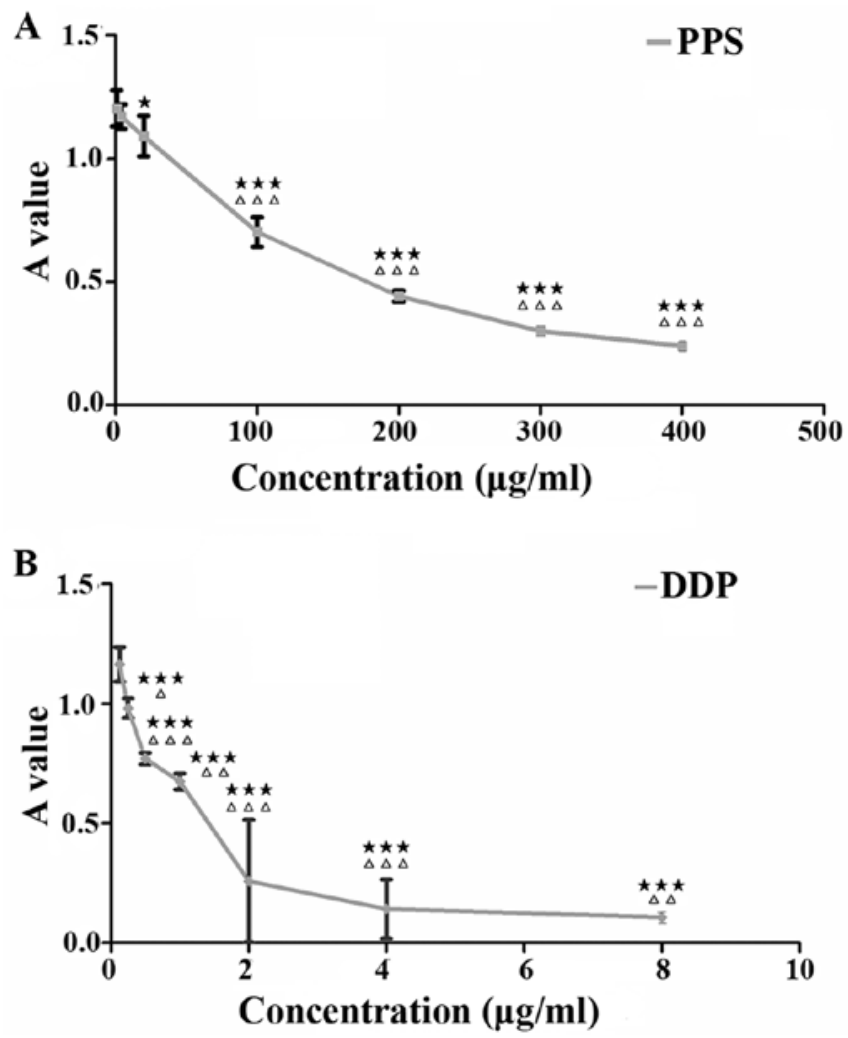

Figure 1. Effect of PPS extract and cisplatin on the proliferation inhibition of SKOV3 cells. (A) Cells were cultured in 10\% FBS medium and treated with PPS $(0.8,4,20,100,200,300,400 \mu \mathrm{g} / \mathrm{ml})$ for $72 \mathrm{~h}$. (B) Cisplatin (DDP) $(0.125,0.25,0.5,1.0,2.0,4.0,8.0 \mu \mathrm{g} / \mathrm{ml})$ was used as the positive control. Each group was replicated six times. Absorption value was expressed as mean \pm SD from six independent experiments. Black pentangle indicates statistical difference between experimental group and blank control group $\left({ }^{\star} \mathrm{P}<0.05,{ }^{\star \star} \mathrm{P}<0.01,{ }^{\star \star} \mathrm{P}<0.001\right)$. White triangle indicates statistical difference between certain concentration group and the next higher concentration group treated with PPS extract or cisplatin $\left({ }^{\Delta} \mathrm{P}<0.05,{ }^{\Delta \Delta} \mathrm{P}<0.01,{ }^{\Delta \Delta \Delta} \mathrm{P}<0.001\right)$.

expression difference between two lines was calculated by the $2^{-\Delta \Delta \mathrm{Ct}}$ method (14).

Statistical methods. All data were first subjected to normality test and expressed as mean \pm standard deviation. Independentsample t-test was used to explore the apoptosis rate and/or proliferation inhibition differences between PPS extract-treated group and control group, cisplatin-treated group and control group, $150 \mu \mathrm{g} / \mathrm{ml}$ PPS extract treatment for 48 and $72 \mathrm{~h}$, and $1 \mu \mathrm{g} / \mathrm{ml}$ cisplatin treatment for 48 and $72 \mathrm{~h}$. Multiple concentrations of PPS extract-treated SKOV3 cells within the same group were compared using one-way ANOVA after homogeneity of variance was tested. LSD method was used to analyze the difference in apoptosis rate between two samples if homogeneity of variance existed. Otherwise, Dunnet's T3 testing was adopted. Data analysis was performed using SPSS software version 16.0.

\section{Results}

Effect of PPS extract on the proliferation of SKOV3 cells. We evaluated the total extract obtained from the PPS. The absorption value of total extract at $660 \mathrm{~nm}$ wavelength was entirely identical to the blank control $(\mathrm{A} 660=0)$ indicating that
A

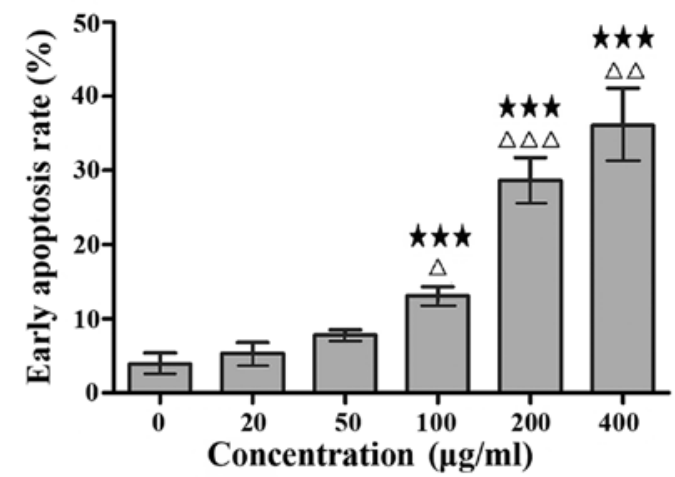

B

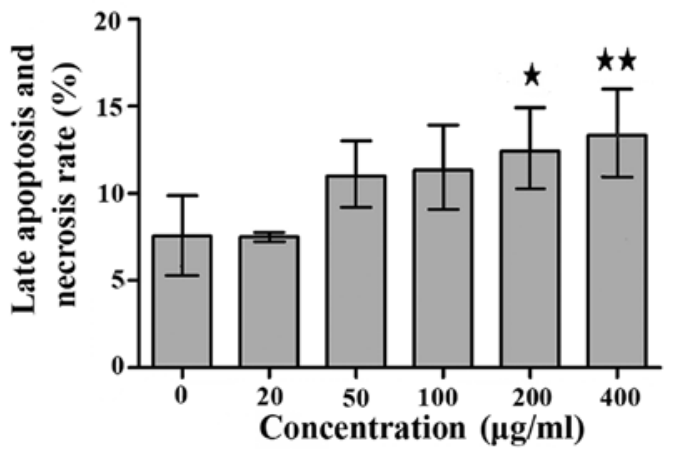

Figure 2. Effects of PPS extract on early apoptosis rate, late apoptosis rate and necrosis rate in SKOV3 cells. Cells were cultured in $10 \%$ FBS medium and treated with PPS $(0,20,50,100,200,400 \mu \mathrm{g} / \mathrm{ml})$ for $72 \mathrm{~h}$. Apoptosis rates are expressed as mean \pm SD from three independent experiments. (A) Early apoptosis rate of SKOV3 cells treated with PPS. (B) Late apoptosis rate and necrosis rate of SKOV3 cells treated with PPS. Black pentangle indicates statistical difference between experimental group and blank control group $\left({ }^{\star} \mathrm{P}<0.05,{ }^{\star \star} \mathrm{P}<0.01,{ }^{\star \star \star} \mathrm{P}<0.001\right)$. White triangle indicates statistical difference between certain concentration group and the next higher concentration group treated with PPS extract $\left({ }^{\Delta} \mathrm{P}<0.05,{ }^{\Delta \Delta} \mathrm{P}<0.01,{ }^{\Delta \Delta \Delta} \mathrm{P}<0.001\right)$.

there was no phosphorus presence. In addition, total extract could not be stained by Sudan dye suggested the absence of lipoprotein. Moreover, total extract can react with $\alpha$-naphthol to generate purple compound indicating the presence of glycoprotein in the extract. The productivity of total protein extracted from fresh PPS was $1 \%(9.97 \mathrm{~g}$ total extract from $1000 \mathrm{~g}$ PPS). We found that $20 \mu \mathrm{g} / \mathrm{ml}$ of the total extract of PPS significantly inhibited the growth of SKOV3 cells in vitro. As the concentration of the PPS extract increased, the inhibition rate was enhanced, showing a significant dose-effect relationship. However, $0.8 \mu \mathrm{g} / \mathrm{ml}$ and $4 \mu \mathrm{g} / \mathrm{ml}$ PPS extract had no obvious effect on cell proliferation inhibition. When the extract protein concentration reached $100 \mu \mathrm{g} / \mathrm{ml}$ or higher, the inhibitory effect of PPS on SKOV3 proliferation was significantly different between the two adjacent concentrations $(\mathrm{F}=407.084, \mathrm{P}<0.001$, Fig. 1A). Cisplatin group also showed a significant dose-effect relationship. The inhibitory effect of cisplatin on SKOV3 cells was significantly different between different concentrations ( $F=799.621$, $\mathrm{P}<0.001$, Fig. 1B).

Effect of the different concentrations of the PPS extract on cell apoptosis rate. We observed that PPS protein extract at higher than $100 \mu \mathrm{g} / \mathrm{ml}$ significantly increased the early apoptosis rate of SKVO3 cells compared with that of the control group (Fig. 2A). PPS extract induced apoptosis of SKOV3 cells in a 
A
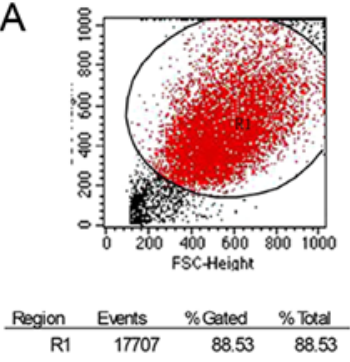

B
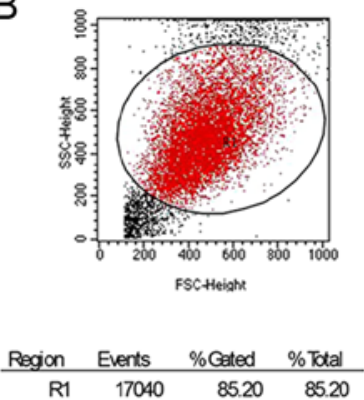
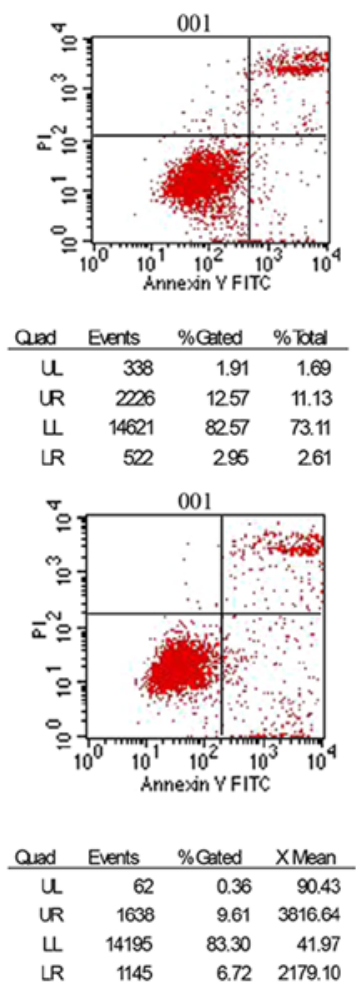
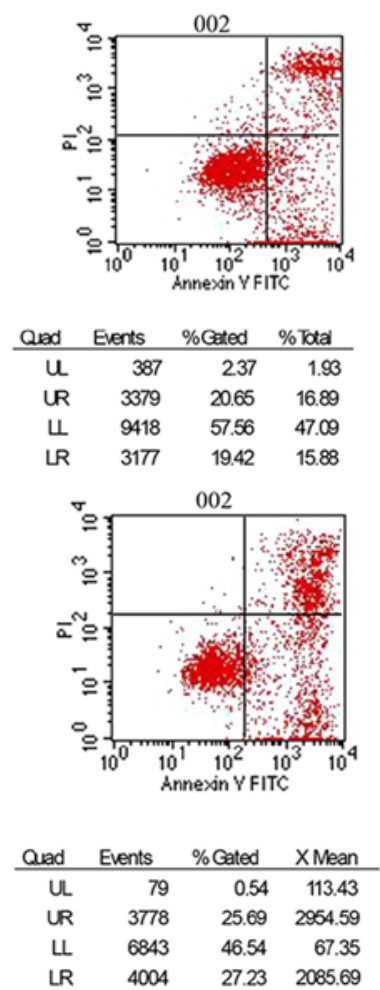
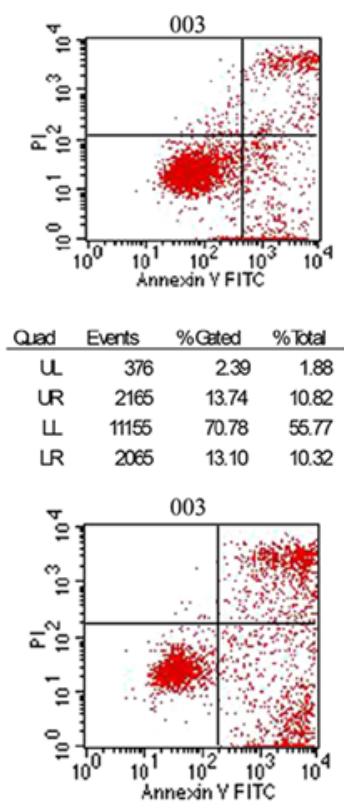

\begin{tabular}{rrrr} 
Quad & Events & \% Gated & X Mean \\
\hline U. & 67 & 0.50 & 97.05 \\
UR & 3292 & 24.66 & 3958.35 \\
$\amalg$ & 6223 & 46.62 & 43.24 \\
LR & 3765 & 28.21 & 3575.03
\end{tabular}

Figure 3. Time-dependent effect of PPS and DDP on the apoptosis rate in SKOV3 cells. (A) Apoptosis rate of SKOV3 cells treated with PPS or DDP for $48 \mathrm{~h}$. (B) Apoptosis rate of SKOV3 cells treated with PPS or DDP for $72 \mathrm{~h} .01$, Control group (medium only); $002, \mathrm{PPS}(150 \mu \mathrm{g} / \mathrm{ml}) \mathrm{group} ; 003, \mathrm{DDP}(1 \mu \mathrm{g} / \mathrm{ml}) \mathrm{group}$; UR, late apoptosis and necrosis; LR, early apoptotic.

dose-dependent manner. When the protein extract concentration increased from $20 \mu \mathrm{g} / \mathrm{ml}$ to $50 \mu \mathrm{g} / \mathrm{ml}$, the early apoptosis rate was slightly increased. However, this rate was significantly increased at extract concentration of $100 \mu \mathrm{g} / \mathrm{ml}$ or higher when compared with the next higher concentration group (Fig. 2A). Only the high concentrations $(200 \mu \mathrm{g} / \mathrm{ml}, 400 \mu \mathrm{g} / \mathrm{ml})$ of PPS extract had significant effects on late cell apoptosis rate and necrosis rate, whereas the low concentrations of PSS protein had no obvious effects (Fig. 2B).

Time-dependent effect of PPS extract on cell apoptosis rate. After the treatment with a relatively high concentration of the PPS extract, SKOV3 cells showed obvious apoptosis, and the apoptosis rate increased with time extension (Fig. 3). The early apoptosis rate in the cells treated with $150 \mu \mathrm{g} / \mathrm{ml}$ PPS protein extract for $48 \mathrm{~h}$ was $14.860 \pm 1.590 \%$, significantly different from the control group $(\mathrm{t}=14.224, \mathrm{P}<0.001)$. Similarly, the early apoptosis rate reached $24.426 \pm 4.149 \%$ after $72 \mathrm{~h}$ treatment with the same extract concentration and the difference between the control group and the treated group was also statistically significant $(\mathrm{t}=8.461, \mathrm{P}=0.001)$. The apoptosis rates of cells treated with $150 \mu \mathrm{g} / \mathrm{ml}$ PPS extract were significantly different between the 48 and $72 \mathrm{~h}$ treatment groups $(\mathrm{t}=3.729, \mathrm{P}=0.02)$.

As a classical chemotherapeutical drug, cisplatin has been widely used to treat various cancers. After the treatment with $1 \mu \mathrm{g} / \mathrm{ml}$ cisplatin for 48 and $72 \mathrm{~h}$, the early apoptosis rates of SKOV3 cells reached $10.033 \pm 2.834 \%$ and $22.470 \pm 6.913 \%$, respectively, both significantly different from the blank control group $(\mathrm{t}=5.116, \mathrm{P}=0.007 ; \mathrm{t}=4.629, \mathrm{P}=0.01$, respectively). The difference between 48 and $72 \mathrm{~h}$ treatment was also statistically significant $(\mathrm{t}=2.877, \mathrm{P}=0.045)$. These data indicated that PPS extract plays a significant role in apoptosis induction of ovarian cancer cell line SKOV3 (Fig. 3).

Transcriptome profiling of SKOV3 and PPS extract-treated SKOV3 and $q P C R$ validation. To reveal how the PPS extract alters the gene expression of SKOV3 cells after $72 \mathrm{~h}$, the transcriptomes of SKOV3 cells and PPS extract-treated SKOV3 cells were sequenced using Illumia/Solexa technology. In total, 44,576,818 and 52,295,034 raw reads with 100 bp in length were obtained from SKOV3 and PPS extract-treated cell lines, respectively. After filtering to exclude low quality, adaptor contamination and ambiguous base containing reads, 43,071,352 and 50,530,232 high quality clean reads remained, representing approximately 4.3 and 5.0 Giga base. We mapped the reads from two cell lines to hg19 genome for quantitative measurement of gene expression and found that 17,217 transcripts were detected as expression. Differential gene expression analysis between two samples showed that 1,754 transcripts were significantly differentially expressed, of which 840 were upregulated and 914 were downregulated in PPS extract-treated group as compared with the untreated group.

To determine in which biochemical pathways these differentially expressed transcripts (DETs) were enrich, total expressed transcripts $(17,217)$ were mapped to the KEGG pathway. Transcripts $(14,135)$ were assigned to 283 pathways representing 23,308 functional occurrences, of which 1,341 annotated transcripts corresponding to 2,365 frequency of use in our indentified DETs. Enrichment analyses were performed 
Table I. Transcript expression difference between SKOV3 and PPS extract-treated SKOV3 cells involved in steroid biosynthesis identified by mRNA-Seq.

\begin{tabular}{lllrrr}
\hline Transcript accession & Protein symbol & Enzyme code & FPKM-SKOV3 & FPKM-PPS & Fold change \\
\hline NM_005891 & ACAT2 & EC:2.3.1.9 & 9.06 & 119.50 & 13.19 \\
NM_002130 & HMGCS1 & EC:2.3.3.10 & 10.94 & 67.12 & 6.13 \\
NM_000859 & HMGCR & EC:1.1.1.34 & 7.56 & 18.69 & 2.47 \\
NM_000431 & MVK & EC:2.7.1.36 & 5.69 & 17.43 & 3.06 \\
NM_006556 & PMVK & EC:2.7.4.2 & 32.00 & 35.38 & 1.11 \\
NM_002461 & MVD & EC:4.1.1.33 & 12.85 & 37.67 & 2.93 \\
NM_001135822 & FDPS & EC:2.5.1.10 & 39.68 & 128.57 & 3.24 \\
NM_001287748 & FDFT1 & EC:2.5.1.21 & 2.68 & 70.79 & 26.38 \\
NM_003129 & SQLE & EC:1.14.99.7 & 17.99 & 68.63 & 3.82 \\
NM_002340 & LSS & EC:5.4.99.7 & 0.0025 & 10.95 & $>1000$ \\
NM_000786 & CYP51A1 & EC:1.14.13.70 & 4.39 & 18.04 & 4.11 \\
NM_015922 & NSDHL & EC:1.1.1.170 & 26.82 & 46.66 & 1.74 \\
NM_001017369 & MSMO1 & EC:1.14.13.72 & 5.13 & 25.47 & 4.97 \\
NM_006745 & MSMO1 & EC:1.14.13.72 & 18.84 & 65.15 & 3.46 \\
NM_001129765 & NSDHL & EC:1.1.1.170 & 1.36 & 4.70 & 3.46 \\
NM_016371 & HSD17B7 & EC:1.1.1.270 & 3.35 & 7.55 & 2.25 \\
NM_006579 & EBP & EC:5.3.3.5 & 10.77 & 3.36 & 0.31 \\
\hline
\end{tabular}

Table II. Primers used in the qPCR.

\begin{tabular}{|c|c|c|}
\hline Gene & Primer name & Sequence $\left(5^{\prime} \rightarrow 3^{\prime}\right)$ \\
\hline 18s rRNA & $\begin{array}{l}\text { 18s rRNA_F } \\
\text { 18s rRNA_R }\end{array}$ & $\begin{array}{l}\text { GGAGCCTGCGGCTTAATTT } \\
\text { CAACTAAGAACGGCCATGCA }\end{array}$ \\
\hline GAPDH & $\begin{array}{l}\text { GAPDH_F } \\
\text { GAPDH_R }\end{array}$ & $\begin{array}{l}\text { CAAATTCCATGGCACCGTCA } \\
\text { GGCAGAGATGATGACCCTTT }\end{array}$ \\
\hline ACAT2 & $\begin{array}{l}\text { ACAT2_F } \\
\text { ACAT2_R }\end{array}$ & $\begin{array}{l}\text { CGGCAGGAGAAGCAAGATGA } \\
\text { GCTGCCAAGACATGTCCAAA }\end{array}$ \\
\hline HMGCS1 & $\begin{array}{l}\text { HMGCS1_F } \\
\text { HMGCS1_R }\end{array}$ & $\begin{array}{l}\text { GCTGCTGTCTTCAATGCTGT } \\
\text { TTTGGCCCAATTAGCAGAGC }\end{array}$ \\
\hline FDPS & $\begin{array}{l}\text { FDPS_F } \\
\text { FDPS_R }\end{array}$ & $\begin{array}{l}\text { AACTACTCGACCCACAGAGC } \\
\text { CTCAGTCAGCACCCTAACGA }\end{array}$ \\
\hline SQLE & $\begin{array}{l}\text { SQLE_F } \\
\text { SQLE_R }\end{array}$ & $\begin{array}{l}\text { GTTCGCCCTCTTCTCGGATA } \\
\text { TGTTGATGTACAGGCAGCTG }\end{array}$ \\
\hline LSS & $\begin{array}{l}\text { LSS_F } \\
\text { LSS_R }\end{array}$ & $\begin{array}{l}\text { CCAGCCGGATACAGAGAAGA } \\
\text { CCACAGCACCACCTTTCTTG }\end{array}$ \\
\hline HSD17B7 & $\begin{array}{l}\text { HSD17B7_F } \\
\text { HSD17B7_R }\end{array}$ & $\begin{array}{l}\text { CGTTTGCTTCACTGCTTGGA } \\
\text { GCTTCTGCCTTGCTCATGTT }\end{array}$ \\
\hline MVK & $\begin{array}{l}\text { MVK_F } \\
\text { MVK_R }\end{array}$ & $\begin{array}{l}\text { CCTGAAGTACAACGCCTCCT } \\
\text { TGCTACCTTGCCATGTACCA }\end{array}$ \\
\hline MVD & $\begin{array}{l}\text { MVD_F } \\
\text { MVD_R }\end{array}$ & $\begin{array}{l}\text { CGATGAAGAGCTGGTTCTGC } \\
\text { CCATCCCGTGAGTTCCTCC }\end{array}$ \\
\hline CYP51A1 & $\begin{array}{l}\text { CYP51A1_F } \\
\text { CYP51A1_R }\end{array}$ & $\begin{array}{l}\text { ACCCTCAGCCTGGTCTACC } \\
\text { GCATCACTCCCCAGAAGGTA }\end{array}$ \\
\hline MSM01 & $\begin{array}{l}\text { MSM01_F } \\
\text { MSM01_R }\end{array}$ & $\begin{array}{l}\text { TGGAACACCTGGCGAGTC } \\
\text { TCCCCATGTTGCAATCTGGA }\end{array}$ \\
\hline
\end{tabular}

using hypergeometric distribution testing followed by multiple hypothesis testing. Result showed that DETs associated with steroid biosynthesis $(\mathrm{q}<0.01)$ were over-represented as 11 of $2,365(0.47 \%)$ DETs could be mapped to this metabolism pathway, whereas the counterparts in the transcriptome background were 32 and 23,308 (0.14\%), respectively. Table I showed the gene expression differences between two groups of cell involved in the steroid biosynthesis.

To evaluate high throughput sequencing data, ten DETs involved in the steroid biosynthesis pathway were selected for qPCR assay. Table II summarized the gene primers used in this qPCR assay. 18s rRNA and GAPDH were used as internal reference to normalize gene expression between two samples. We found that all genes were upregulated in PPS extracttreated cell line compared with untreated SKOV3, which is consistent with the mRNA-Seq data although the exact fold changes for these genes between the two techniques within two cell lines are slightly different (Table III). The correlation coefficients (Pearson) of differential expression ratio between two techniques were 0.895 and 0.896 when $18 \mathrm{~s}$ rRNA and GAPDH were used as internal control for qPCR analysis, respectively (Fig. 4).

\section{Discussion}

Pedate Pinellia Rhizome, the rhizome of PPS, is a common TCM found in the mid-region of China. It has been reported in many TCM books to possess efficacy in dispelling wind, relieving convulsion, drying dampness to eliminate phlegm, eliminating stagnation, and has long been used to cure thanatophidia bite, nameless swelling and toxicum. It has also been shown to have antitumor properties without apparent toxic effects on noncancerous cells $(6,15)$. In this study, total extract obtained from PPS was used to investigate apoptosis 
A

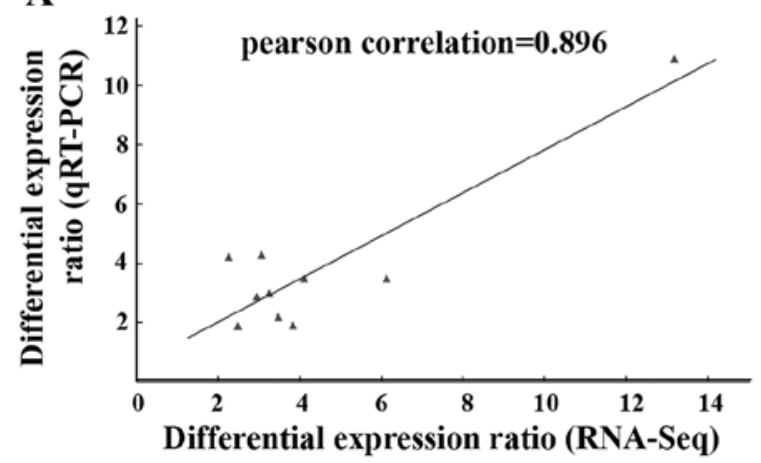

B

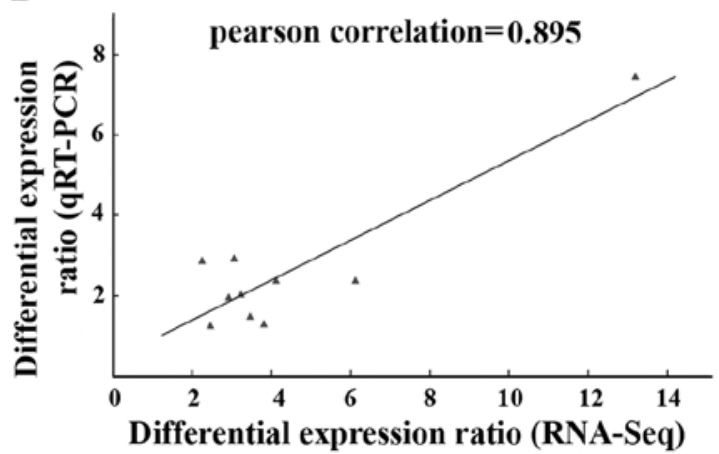

Figure 4. Pearson correlation coefficient of differential expression ratios between mRNA-Seq and qRT-PCR. Correlation was significant at the 0.01 level. GAPDH was used as internal control. (B) 18s rRNA was used as internal control.

Table III. qPCR validation of ten DETs involved in the steroid biosynthesis pathway.

\begin{tabular}{lcccccccccc}
\hline & \multicolumn{7}{c}{ Relative fold difference of transcript } & abundance between SKOV3 and PPS protein-treated SKOV3 \\
\cline { 2 - 10 } $\begin{array}{l}\text { Endogenous } \\
\text { control }\end{array}$ & ACAT2 & HMGCS1 & FDPS & SQLE & LSS & HSD17B7 & MVK & MVD & CYP51A1 & MSM01 \\
\hline 18s rRNA & 7.46 & 2.40 & 2.05 & 1.31 & 1.97 & 2.89 & 2.95 & 1.97 & 2.40 & 1.51 \\
GAPDH & 10.90 & 3.50 & 2.99 & 1.92 & 2.87 & 4.22 & 4.30 & 2.88 & 3.50 & 2.20 \\
\hline
\end{tabular}

Table IV. Transcript expression difference between SKOV3 and PPS extract-treated SKOV3 cells involved in apoptosis identified by mRNA-Seq.

\begin{tabular}{llccc}
\hline Transcript accession & Protein symbol & FPKM-SKOV3 & FPKM-PPS & Fold change \\
\hline NM_032991 & CASP3 variant $\beta$ & 2.7 & 8.85 & 3.27 \\
NM_033356 & CASP8 variant C & 0 & 3.11 & Inf \\
NM_001229 & CASP9 variant $\alpha$ & 0.0008 & 3.23 & $>1000$ \\
NM_001267056 & CASP7 variant e & 14.77 & 4.18 & 0.28 \\
NM_001227 & CASP7 variant a & 0.66 & 6.58 & 9.96 \\
NM_032974 & CASP10 variant 2 & 0.36 & 4.53 & 12.72 \\
NM_001204401 & XIAP variant 2 & 0.0022 & 4.14 & $>1000$ \\
NM_001012270 & BIRC5 variant 2 & 1.54 & 5.42 & 3.52 \\
NM_001171625 & VEGFA variant 3 & 8.71 & 0.09 & 0.01 \\
NM_001243733 & VEGFB-167 & 12.6 & 0 & 0 \\
NM_198156 & VHL variant 2 & 0.13 & 3.65 & 28.1 \\
NM_004465 & FGF10 & 6.11 & 0 & 0 \\
\hline
\end{tabular}

induction and proliferation inhibition ability against ovarian cancer cell line SKOV3. Cisplatin, the most commonly used chemotherapy drug in ovarian cancer, was used as the positive control. Results showed that only low concentrations of PPS protein extract $(20 \mu \mathrm{g} / \mathrm{ml})$ had obvious inhibitory effect on cell proliferation, whereas high concentrations of PPS extract $(\geq 100 \mu \mathrm{g} / \mathrm{ml})$ significantly increased the early apoptosis rate of SKOV3 cells. In addition, the early apoptosis rate was also significantly increased when the treatment time was extended from 48 to $72 \mathrm{~h}$ under the same extract concentration $(150 \mu \mathrm{g} /$ $\mathrm{ml})$. These results indicated that the extract of PPS could induce apoptosis in ovarian cancer cell SKOV3 in a dose- and time-dependent manner.

Transcriptome sequencing and quantitative gene expression analysis identified 1,754 DETs between SKOV3 and PPS extract-treated cells. These DETs were significantly enriched in the steroid biosynthesis pathway. In this pathway, we found that most of the enzymes responsible for the synthesis from farnesyl-diphosphate to 3-keto-4-methylzymosterol were significantly upregulated in response to PPS treatment (Tables I and III). Of note, many genes involved in the synthesis of farnesyl-diphosphate, the original substrate of the 


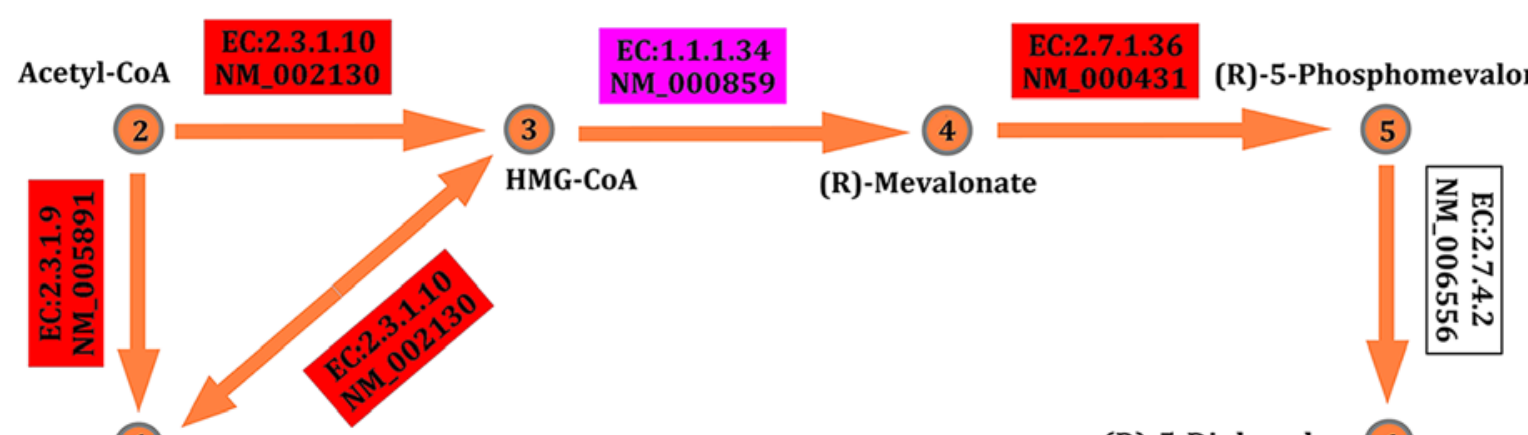

1

(R)-5-Diphospho-

Acetoacetyl-CoA mevalonate

\section{4alpha-Methyl- zymosterol}

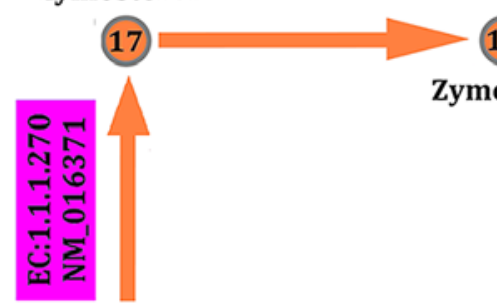

16) 3-Keto-4-methylzymosterol
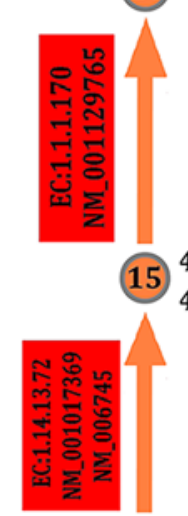

15

4alpha-Methylzymosterol4-carboxylate

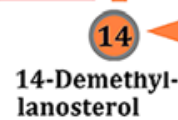

14 lanosterol

Zymosterol
18

\section{EC:5.3.3.5}

NM_006579

5alpha-Cholesta-7,24-dien-3beta-ol

\section{(19)}

Isopentenyl diphosphate

\section{(6)}

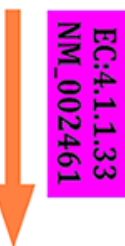

(7)

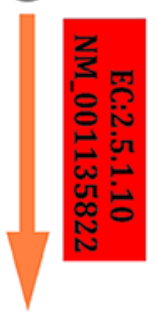

Farnesyl diphosphate

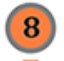

8

Figure 5. Differentially expressed transcripts (DETs) between SKOV3 and PPS extract-treated SKOV3 cells involved in zymosterol biosynthesis. Red, significantly upregulated transcripts ( $>3$-fold) in PPS extract-treated group compared with control group. Pink, 2-3-fold upregulated transcripts in PPS extract-treated group. Green, significantly downregulated transcripts (<1/3-fold) in PPS extract-treated group.

steroid biosynthesis, were significantly upregulated, although not enriched, in the terpenoid backbone biosynthesis pathway. These upregulated DETs constituted a relatively intact reaction chain associated with the synthesis of acetyl-CoA to 3-keto-4-methylzymosterol, indicative of increased accumulation of zymosterol in the PPS extract-treated cells. Validation of transcriptome sequencing data by using qPCR also showed that genes associated with the zymosterol biosynthesis were significantly upregulated after treated with PPS extract.
In addition, the cholestenol delta-isomerase, which is enzymatically involved in the catalysis of zymosterol to 5alpha-Cholesta-7,24-dien-3beta-ol, was downregulated, further suggesting the retained accumulation of zymosterol in PPS extract-treated cells (Fig. 5). Furthermore, the expression of genes encoding the down-stream enzymes in the steroid biosynthesis pathway were not significantly differential, suggesting that the final product for majority of farnesyldiphosphate may not be cholesterol or other secosteroid, such 
as vitamine D2, but zymosterol or its precursor. Zymosterol, an intermediate precursor of cholesterol, was located in the plasma membrane of human cells and has been considered to play an important role in regulating membrane fluidity and permeability (16-18). Previous studies have demonstrated that compounds derived from the isoprenoid/cholesterol biosynthetic pathway possessed novel biological activities, such as regulating transcriptional and post-transcriptional events that in turn affect lipid synthesis, meiosis, apoptosis, developmental patterning, protein cleavage, as well as protein degradation (19). The upregulated expression of enzymes encoding genes involved in the biosynthesis of zymosterol may be closely related to the increase of cell apoptosis rate after PPS extract treatment.

To date, two classical apoptosis signaling pathways (the extrinsic and intrinsic pathways) have been well established $(20,21)$. The extrinsic pathway is initiated by the extracellular hormones or agonists that can be recognized by the cell surface death receptors (22). The activation of intrinsic pathway can be initiated by the release of cytochrome $\mathrm{c}$ or SMAC/DIABLO from mitochondria (21). Programmed cell death (PCD) from both signaling pathways can be finally ascribed to caspase activation, including the initiator, such as caspase-8, -9, -10, and the executioner, such as caspase-3 and -7. Since treatment of SKOV3 cells with $100 \mu \mathrm{g} / \mathrm{ml}$ or higher PPS extract significantly increased the apoptosis rate, it is possible that the expression level of genes participated in PCD might have changed. As expected, the expression of the caspase family members, including caspase- $3 \beta,-7 \mathrm{a},-8 \mathrm{c},-9 \alpha$ and caspase-10 variant 2 , were significantly upregulated in PPS extract-treated group, except for caspase-7e, which was downregulated (Table IV). These upregulated caspases may well explain the increase of cell apoptosis rates.

Controversially, the inhibitors of apoptosis (IAP) protein, such as BIRC5 (Survivin) and XIAP, which inhibit caspase activity by directly binding to the enzyme, were also significantly upregulated $(23,24)$. The overexpressed IAP family members in PPS group might also result from the cell antiapoptotic response, which in turn antagonized the upregulated caspase activity. However, the enhanced xIAP activity in PPS-treated cells might not be antagonized by the second mitochondrial-derived activator of caspase (SMAC/DIABLO), because the expression of SMAC-encoded transcript variants was not upregulated. In addition, few cytosolic pro-apoptotic Bcl-2 family members that can promote cytochrome c release from mitochondria to cytosol, such as Bid, Bax, Bak, Bad, were upregulated. Taken together, the PPS extract-induced PCD in SKOV3 cells may initially be mediated by the extrinsic apoptosis signaling pathway.

Vascular endothelial growth factor (VEGF) has been suggested to be a key regulator of angiogenesis in many types of cancer, including ovarian cancer $(25,26)$. Due to alternative splicing events, a number of VEGF mRNA variants have been detected and all variants are derived from the same locus in human genome (27). VEGF induces endothelial cell proliferation presumably through binding to the endothelial cell receptor. Elevated VEGF expression across a wide range of cancers has been observed, such as breast cancer and ovarian cancer $(28,29)$. We found that VEGFA variant 3 and VEGFB-167 were moderately expressed in SKOV3 cell line.
However, the expression of these two variants was extremely downregulated in PPS extract-treated cell line, where FPKM values were almost undetectable (Table IV). This may be due to the enhanced von Hippel-Lindau tumor suppressor (VHL) expression in PPS extract-treated group. VHL possesses ubiquitin ligase E3 activity and is a well-characterized VEGF transcriptional repressor, which inhibits VEGF expression through direct ubiquitination and subsequent degradation of its transcription factor $(30,31)$, hypoxia-inducible-factor (HIF). For other hormones, FGF10 was moderately expressed in SKOV3 cells, whereas its expression was not detected in PPS-treated cells. FGF10 has been proven to play an important role in tumor growth and invasion in a variety of cancers, such as breast cancer and pancreatic cancer $(32,33)$. The downregulated FGF10 expression was consistent with the low proliferation ability in response to PPS extract treatment.

In conclusion, total extract obtained from PPS can inhibit epithelial derived ovarian cancer cell line SKOV3 proliferation and further induce apoptosis of these cells in a dose- and time-dependent manner, indicative of PPS extract component as a potential drug for ovarian cancer treatment in the future. Transcriptome sequencing and differential gene expression analysis revealed that the expression of a number of caspase family members were upregulated after PPS extract treatment. This result is mechanistically consistent with the obvious apoptotic phenotype and increased apoptosis rate of SKOV3 cells measured by flow cytometry.

In addition, many differentially expressed transcripts involved in the synthesis of steroid were significantly upregulated and over-represented, suggesting that cell apoptosis induced by extract of PPS might be accompanied by the increased biosynthesis of steroid, probably zymosterol. Therefore, this steroid could be considered as a novel regulator during ovarian cancer cell apopotsis after treated with PPS extract.

\section{Acknowledgements}

This work was supported by Science and Technology Foundation of Wenzhou City, China (H20100011), Zhejiang Provincial Science and Technology Foundation of Chinese Medicine, China (2012ZB106), Foundation of Science and Technology Innovation Team of Zhejiang Province, China (2010R50048-13) and Research Initial Funding in Wenzhou Medical University (QTJ14002).

\section{References}

1. Zhang L, Huang J, Yang N, Greshock J, Megraw MS, Giannakakis A, Liang S, Naylor TL, Barchetti A, Ward MR, et al: microRNAs exhibit high frequency genomic alterations in human cancer. Proc Natl Acad Sci USA 103: 9136-9141, 2006.

2. Yap TA, Carden CP and Kaye SB: Beyond chemotherapy: Targeted therapies in ovarian cancer. Nat Rev Cancer 9: 167-181, 2009.

3. Eisenhauer EL, Tew WP, Levine DA, Lichtman SM, Brown CL, Aghajanian C, Huh J, Barakat RR and Chi DS: Response and outcomes in elderly patients with stages IIIC-IV ovarian cancer receiving platinum-taxane chemotherapy. Gynecol Oncol 106: 381-387, 2007.

4. Boren T, Xiong Y, Hakam A, Wenham R, Apte S, Chan G, Kamath SG, Chen DT, Dressman $\mathrm{H}$ and Lancaster JM: MicroRNAs and their target messenger RNAs associated with ovarian cancer response to chemotherapy. Gynecol Oncol 113: 249-255, 2009. 
5. Li SD, Zhang JR, Wang YQ and Wan XP: The role of microRNAs in ovarian cancer initiation and progression. J Cell Mol Med 14: 2240-2249, 2010.

6. Li GL, Jiang W, Xia Q, Chen SH, Ge XR, Gui SQ and Xu CJ: HPV E6 down-regulation and apoptosis induction of human cervical cancer cells by a novel lipid-soluble extract (PE) from Pinellia Pedatisecta Schott in vitro. J Ethnopharmacol 132: 56-64, 2010

7. Sun GX, Ding SS and Qian YJ: The extraction and chemical analysis of proteins from Pinellia Pedatisecta and their inhibitory effects on the mouse sarcoma-180. Acta Academiae Medicinae Shanghai 19: 17-20, 1992.

8. Bolger AM, Lohse M and Usadel B: Trimmomatic: A flexible trimmer for Illumina sequence data. Bioinformatics 30 2114-2120, 2014

9. Trapnell C, Pachter L and Salzberg SL: TopHat: Discovering splice junctions with RNA-Seq. Bioinformatics 25: 1105-1111, 2009.

10. Trapnell C, Roberts A, Goff L, Pertea G, Kim D, Kelley DR, Pimentel H, Salzberg SL, Rinn JL and Pachter L: Differential gene and transcript expression analysis of RNA-seq experiments with TopHat and Cufflinks. Nat Protoc 7: 562-578, 2012.

11. Trapnell C, Hendrickson DG, Sauvageau M, Goff L, Rinn JL and Pachter L: Differential analysis of gene regulation at transcript resolution with RNA-seq. Nat Biotechnol 31: 46-53, 2013.

12. Kanehisa M and Goto S: KEGG: Kyoto encyclopedia of genes and genomes. Nucleic Acids Res 28: 27-30, 2000.

13. Ma X, Wehland M, Aleshcheva G, Hauslage J, Wasser K, Hemmersbach R, Infanger M, Bauer J and Grimm D: Interleukin-6 expression under gravitational stress due to vibration and hypergravity in follicular thyroid cancer cells. PLoS One 8: e68140, 2013.

14. Livak KJ and Schmittgen TD: Analysis of relative gene expression data using real-time quantitative PCR and the 2(-Delta Delta C(T)) method. Methods 25: 402-408, 2001.

15. Li GL, Gui SQ and Zhu DH: Effects of pinellia extraction only or combined with cisplatin on growth of Hela cells of cervical cancer. Fudan Univ J Med Sci 34: 869-872, 2007.

16. Echevarria F, Norton RA, Nes WD and Lange Y: Zymosterol is located in the plasma membrane of cultured human fibroblasts. $J$ Biol Chem 265: 8484-8489, 1990.

17. Lange Y, Echevarria F and Steck TL: Movement of zymosterol, a precursor of cholesterol, among three membranes in human fibroblasts. J Biol Chem 266: 21439-21443, 1991.

18. Brown DA and London E: Structure and function of sphingolipid- and cholesterol-rich membrane rafts. J Biol Chem 275: 17221-17224, 2000.

19. Edwards PA and Ericsson J: Sterols and isoprenoids: Signaling molecules derived from the cholesterol biosynthetic pathway. Annu Rev Biochem 68: 157-185, 1999.
20. Strasser A, O'Connor L and Dixit VM: Apoptosis signaling. Annu Rev Biochem 69: 217-245, 2000.

21. Jiang X and Wang X: Cytochrome C-mediated apoptosis. Annu Rev Biochem 73: 87-106, 2004.

22. Ashkenazi A and Dixit VM: Death receptors: Signaling and modulation. Science 281: 1305-1308, 1998.

23. Deveraux QL and Reed JC: IAP family proteins - suppressors of apoptosis. Genes Dev 13: 239-252, 1999.

24. Bratton SB, Walker G, Srinivasula SM, Sun XM, Butterworth M, Alnemri ES and Cohen GM: Recruitment, activation and retention of caspases- 9 and -3 by Apaf- 1 apoptosome and associated XIAP complexes. EMBO J 20: 998-1009, 2001.

25. Boocock CA, Charnock-Jones DS, Sharkey AM, McLaren J, Barker PJ, Wright KA, Twentyman PR and Smith SK: Expression of vascular endothelial growth factor and its receptors flt and KDR in ovarian carcinoma. J Natl Cancer Inst 87: 506-516, 1995.

26. Duyndam MC, Hilhorst MC, Schlüper HM, Verheul HM, van Diest PJ, Kraal G, Pinedo HM and Boven E: Vascular endothelial growth factor- 165 overexpression stimulates angiogenesis and induces cyst formation and macrophage infiltration in human ovarian cancer xenografts. Am J Pathol 160: 537-548, 2002.

27. Tischer E, Mitchell R, Hartman T, Silva M, Gospodarowicz D, Fiddes JC and Abraham JA: The human gene for vascular endothelial growth factor. Multiple protein forms are encoded through alternative exon splicing. J Biol Chem 266: 11947-11954, 1991.

28. Takahashi Y, Kitadai Y, Bucana CD, Cleary KR and Ellis LM: Expression of vascular endothelial growth factor and its receptor, KDR, correlates with vascularity, metastasis, and proliferation of human colon cancer. Cancer Res 55: 3964-3968, 1995.

29. Leng R, Zha L and Tang L: MiR-718 represses VEGF and inhibits ovarian cancer cell progression. FEBS Lett 588: 2078-2086, 2014.

30. Iliopoulos O, Levy AP, Jiang C, Kaelin WG Jr and Goldberg MA: Negative regulation of hypoxia-inducible genes by the von Hippel-Lindau protein. Proc Natl Acad Sci USA 93: 10595-10599, 1996.

31. Maxwell PH, Wiesener MS, Chang GW, Clifford SC, Vaux EC, Cockman ME, Wykoff CC, Pugh CW, Maher ER and Ratcliffe PJ: The tumour suppressor protein VHL targets hypoxia-inducible factors for oxygen-dependent proteolysis. Nature 399: 271-275, 1999.

32. Nomura S, Yoshitomi H, Takano S, Shida T, Kobayashi S, Ohtsuka M, Kimura F, Shimizu H, Yoshidome H, Kato A, et al: FGF10/FGFR2 signal induces cell migration and invasion in pancreatic cancer. Br J Cancer 99: 305-313, 2008.

33. Sugimoto K, Yoshida S, Mashio Y, Toyota N, Xing Y, Xu H, Fujita Y, Huang Z, Touma M and Wu Q: Role of FGF10 on tumorigenesis by MS-K. Genes Cells 19: 112-125, 2014. 